\title{
Microsatellite analysis of genetic diversity in the Tupaia belangeri yaoshanensis
}

\author{
AO-LEI SU ${ }^{1,3^{*}}$, XIU-WAN LAN ${ }^{2 *}$, MING-BO HUANG ${ }^{4}$, WEI NONG ${ }^{1}$, QINGDI QUENTIN LI ${ }^{5}$ and JING LENG $^{1}$ \\ ${ }^{1}$ Department of Microbiology and Immunology, Key Laboratory for Complementary and \\ Alternative Medicine Experimental Animal Models of Guangxi, Guangxi University of Chinese Medicine, Nanning, \\ Guangxi 530001; ${ }^{2}$ Department of Biochemistry and Molecule Biology, Guangxi Colleges and Universities \\ Key Laboratory of Preclinical Medicine Research, Guangxi Colleges and Universities Key Laboratory of \\ Biological Molecular Medicine Research, Guangxi Medical University, Nanning, Guangxi 530021; \\ ${ }^{3}$ Department of Basic Medical Training Center, Guangxi Medical College, Nanning, Guangxi 530021, P.R. China; \\ ${ }^{4}$ Department of Microbiology, Biochemistry and Immunology, Morehouse School of Medicine, \\ Atlanta, GA 30310; ${ }^{5}$ National Institutes of Health, Bethesda, MD 20892, USA
}

Received July 27, 2017; Accepted August 4, 2017

DOI: $10.3892 /$ br.2017.969

\begin{abstract}
The Chinese tree shrew (Tupaia belangeri yaoshanensis) has long been proposed to serve as an animal model for studying human diseases. However, its overall genetic diversity and population structure remain largely unknown. In the present study, we investigated the genetic diversity of population microsatellite DNA in wild Tupaia belangeri yaoshanensis. Sixteen microsatellite loci were assessed in 76 wild Tupaia belangeri yaoshanensis. The target microsatellite DNA fragments were amplified from the peripheral blood DNA of the animals by polymerase chain reaction (PCR), and the PCR-amplified products were verified by DNA sequencing and used for the analysis of allele, effective allele, genetic heterozygosity, polymorphism and population structure. Our results showed that of the 16 microsatellite loci examined, 5 microsatellite loci were monomorphic and 11 microsatellite loci were polymorphic. We detected 61 alleles in the polymorphic loci and found 2-10 (with an average of 5.5455) alleles per locus. Our data also showed that the observed and expected heterozygosities ranged from 0.087 to 0.8947 and 0.1368 to 0.7892 with an average of 0.3968 and 0.4796 , respectively. Taken together, the results revealed a considerably high heterozygosity and high genetic diversity at the molecular level in
\end{abstract}

Correspondence to: Dr Jing Leng, Department of Microbiology and Immunology, Key Laboratory for Complementary and Alternative Medicine Experimental Animal Models of Guangxi, Guangxi University of Chinese Medicine, 13 Wu He Road, Nanning, Guangxi 530200, P.R. China

E-mail: jingleng.gx@hotmail.com

*Contributed equally

Key words: Tupaia belangeri yaoshanensis, microsatellite, population genetic diversity the population of wild Tupaia belangeri yaoshanensis. The identified markers from the present study may be useful for individual identification and parentage testing, as well as for the quantification of population heterogeneity in the Chinese tree shrew.

\section{Introduction}

Microsatellite markers, or short tandem repeats (STR), are polymorphic DNA loci containing repeated nucleotide sequences, typically from 2 to 7 nucleotides per unit. The length of the repeated unit is the same for the majority of the repeats within an individual microsatellite locus. By contrast, when the number of repeats for a specific locus differs, it results in alleles of varying length (1). The vast amount of data emerging for thousands of microsatellite markers across organisms makes microsatellite analysis a widely accepted tool for population genetic diversity studies, as well as for identifying individual organisms, including human and tree shrew. Microsatellite analysis includes polymerase chain reaction (PCR) amplification of the microsatellite loci using fluorescently labeled primers. The labeled PCR products are then analyzed by capillary electrophoresis or electrophoresis to separate the alleles by size (2). In the present study, we used and developed this microsatellite analysis for identifying the individual Chinese tree shrew.

Tree shrew (Scandentia, Tupaiidae) is a small mammal with a close affinity to primates. It belongs to the Family Tupaiidae of Scandentia and is native to tropical forests, widely distributed across Southeast Asia (3). The Chinese tree shrew (Tupaia belangeri) is distributed across southwest China and classified as six subspecies (Tupaia belangeri chinensis, Tupaia belangeri gaoligongensis, Tupaia belangeri modesta, Tupaia belangeri tonquinia, Tupaia belangeri yunalis and Tupaia belangeri yaoshanensis) based on morphological characteristics and geographical distribution. Tupaia belangeri yaoshanensis is the largest in size. It inhabits the Dayaoshan Mountain of Guangxi, 
China. Owing to its resemblance of ancestral primates $(4,5)$, as well as their behavior and social monogamy (6), the Chinese tree shrew has been used as an experimental animal models for the study of human diseases (7).

Although some mitochondrial (mtDNA) and nuclear (nDNA) sequences and karyotype maps have been published $(6,8,9)$ correctly, there few species or population level studies on the Chinese tree shrew. Microsatellite markers are an extremely important tool for genetic studies and for the conservation and management of genetic resources $(10,11)$. Previous studies identified microsatellite markers of tree shrew (2,12-14); however, microsatellite markers specific to Tupaia belangeri yaoshanensis remain to be determined. For the conservation of genetic resources or for selecting a proper founder to establish the inbred lines, it would be worthwhile to screen the genetic diversity of these different subspecies (12).

In this study, we analyzed 16 microsatellite loci of genomic DNAs from a population of 76 individuals of wild Tupaia belangeri yaoshanensis by using the microsatellites developed from other subspecies of tree shrews, and evaluated the genetic diversity of this population. Our study suggests that these 16 microsatellite markers can be used to analyze the population genetics of Tupaia belangeri yaoshanensis and to establish animal models. Moreover, the findings of this study can be used for the protection and effective utilization of the germplasm resource of this species.

\section{Materials and methods}

Sample collection. Seventy-six wild Tupaia belangeri yaoshanensis animals were collected from the Dayaoshan Mountain of Guangxi, China and were used in this study. All the animals were raised at the Experimental Animal Center of Guangxi University of Chinese Medicine under specific pathogenfree conditions and were cared for in an environmentally controlled room with a 12-h light/dark cycle and a constant temperature of $22^{\circ} \mathrm{C}$. The animals were provided with a standard diet and water in accordance with the guidelines for the treatment of experimental animals published by the Ministry of Science and Technology of the People's Republic of China in 2006. Genomic DNA was extracted from the blood of tail tissues of each individual Tupaia belangeri yaoshanensis by using the genomic DNA extraction kit (Tiangen, Beijing, China). All sampling procedures related to animal subjects were reviewed and approved by the Review Committee of Guangxi University of Chinese Medicine, in accordance with the institutional animal care and use regulations and rules. The present study was carried out in strict accordance with the recommendations established in the Guide for the Care and Use of Laboratory Animals of the National Institutes of Health (eighth version, 2010). The animal use protocols were reviewed and approved by the Institutional Animal Care and Use Committee of Guangxi University of Chinese Medicine (Nanning, China; approval nos. GXUCM2014NSF01125 and GXUCM2014NSF01136).

Microsatellite screening and simple sequence repeat (SSR) analysis. Sixteen previously described microsatellite loci of other species of tree shrews were used in this study (Table I). The composition of the PCR reaction mixture and procedures of PCR were referenced as per the published methods $(2,12-14)$, with minor modifications. Briefly, the PCR amplification was performed in $25 \mu \mathrm{l}$ volumes containing $1 \mu \mathrm{l}$ diluted DNA template, $1 \mu \mathrm{l}$ forward and reverse primers (the forward primer was fluorescently labeled with FAM, HEX or TAM), $2.5 \mu 1$ 10X PCR buffer [without $\mathrm{Mg}^{2+}$ : $100 \mathrm{mM}$ Tris-HCl pH 8.8; $500 \mathrm{mM} \mathrm{KCl}, 0.8 \%$ (v/v) Nonidet], $0.5 \mu \mathrm{l} 10 \mathrm{mM}$ dNTPs, $2 \mu \mathrm{l}$ $25 \mathrm{mM} \mathrm{MgCl}_{2}$, and $0.2 \mu 15$ units TaqDNA polymerase (Takara Bio Inc., Otsu, Japan), and $17.8 \mu \mathrm{l}$ sterilized water. Amplification was performed on an Applied Biosystems (T100; Bio-Rad, Hercules, CA, USA). Thermal cycling conditions were implemented as follows: $94^{\circ} \mathrm{C}$ for $3 \mathrm{~min}$; followed by 30 cycles of $95^{\circ} \mathrm{C}$ for $30 \mathrm{sec}$, optimal annealing temperature (Table I) for $30 \mathrm{sec}, 72^{\circ} \mathrm{C}$ for $30 \mathrm{sec}$, a final extension step at $72^{\circ} \mathrm{C}$ for $5 \mathrm{~min}$ and then holding at $8^{\circ} \mathrm{C}$. PCR product $(1 \mu \mathrm{l})$ was mixed with $0.1 \mu \mathrm{l} \mathrm{GeneScan}{ }^{\mathrm{TM}} 500 \mathrm{LIZ}^{\circledR}$ and $9.9 \mu \mathrm{l} \mathrm{Hi-Di}{ }^{\mathrm{TM}}$ Formamide and denatured at $95^{\circ} \mathrm{C}$ for $5 \mathrm{~min}$, then immediately chilled on ice. After this, it was separated on an ABI PRISM $3730 \mathrm{XL}$ genetic analyzer (Applied Biosystems, Foster City, CA, USA).

Statistical data analysis. For each locus in the population, the number of alleles $\left(N_{\mathrm{A}}\right)$, effective number of alleles $\left(N_{\mathrm{E}}\right)$, observed heterozygosity $\left(H_{\mathrm{O}}\right)$, expected heterozygosity $\left(H_{\mathrm{E}}\right)$, and fixation index (Fis), as well as tests for deviation from Hardy-Weinberg equilibrium (HWE), were analyzed using Popgene version 1.32 (15). Allele frequency data were used to calculate polymorphic information content (PIC) using the methods described by Botstein et al (16).

\section{Results}

The details of variability measurement across 76 individuals of the Tupaia belangeri yaoshanensis are summarized in Table II. Among the 16 microsatellites, seven were perfect (43.75\%), four were imperfect $(25 \%)$, and five turned out to be compound $(31.25 \%)$.

Overall, 11 loci $(68.75 \%)$ were cleanly amplified and were shown to be polymorphic. We identified 2-10 alleles (with an average of 5.5455 alleles) per locus in these polymorphic markers. TB2 with 10 alleles was the most polymorphic microsatellite, while TB3 and TB8 were the least variable with only 2 alleles each. The effective number of alleles per locus ranged from 1.16 at TB3 to 4.63 at TG1, with an average of 2.3975. The observed and expected heterozygosities were 0.087 to 0.8947 and 0.1368 to 0.7892 (with an average of 0.3968 and 0.4796 ), respectively. The $F$ is pronounced the most loci with heterozygote deficiencies. Seven loci (JS188, JS196, TB2, TB10, TB20, TBC10 and TBC11) significantly deviated from the HWE in the sampled population after Bonferroni's correction. The average PIC per locus ranged from 0.1266 to 0.7505 (Table II), of which, three loci showed low polymorphism (PIC <0.25), four loci showed median polymorphism $(0.25<$ PIC $<0.5)$, while the other four loci were all high polymorphism (PIC $>0.5$ ).

In this study, we detected 16 population-loci out of the 35 population-loci examined, as we tested non-specific amplification in some loci in our samples. We showed that five $(31.25 \%)$ (TBC1, TBC3, TBC5, TG4 and TG19) were monomorphic, and they failed to amplify in Tupaia belangeri yaoshanensis, and these population-loci were proved to be 
Table I. PCR primers and their sequences for the 16 microsatellite loci used in this study.

\begin{tabular}{|c|c|c|c|c|c|}
\hline Locus & $\begin{array}{l}\text { Primer sequences } \\
\qquad\left(5^{\prime} \rightarrow 3^{\prime}\right)\end{array}$ & $\begin{array}{l}\mathrm{Tm} \\
\left({ }^{\circ} \mathrm{C}\right)\end{array}$ & Repeat motif & $\begin{array}{l}\text { Size range } \\
\quad(\mathrm{bp})\end{array}$ & $\begin{array}{l}\text { Accession no./ } \\
\text { (Refs.) }\end{array}$ \\
\hline JS188 & $\begin{array}{l}\text { F: ACACACACAAAACTCATTTTATCC } \\
\text { R: TCTACACGAATGTGCCAACC }\end{array}$ & 57 & $(\mathrm{CA}) \mathrm{n}$ & $186-196$ & DQ-334279 \\
\hline JS196 & $\begin{array}{l}\text { F: ACCTCCTGGTGGCTTGC } \\
\text { R: TAATTGCAGGATGCTTCAGG }\end{array}$ & 57 & $(\mathrm{GT}) \mathrm{n}$ & $304-344$ & DQ-334280 \\
\hline TB2 & $\begin{array}{l}\text { F: AATATGCTGGTAGGACCAGAAAC } \\
\text { R: ATTGGGTTGTTGGGAAAGTC }\end{array}$ & 60 & (AAG)n(GAGAA)n & $189-275$ & (11) \\
\hline TB3 & $\begin{array}{l}\text { F: TCTGGACCTAGCAACTTGCTTTC } \\
\text { R: TTCTTCACCAGTGTTGAGCATAA }\end{array}$ & 58 & (TAAA)n & $254-259$ & (11) \\
\hline TB8 & $\begin{array}{l}\text { F: CTCTGACTTCAAGACCTGGAAC } \\
\text { R: CTTGAAAGCAAAGGCAGTACAA }\end{array}$ & 55 & $((\mathrm{~A} / \mathrm{G}) \mathrm{TC}(\mathrm{C} / \mathrm{T})) \mathrm{n}$ & $453-465$ & (11) \\
\hline TB 10 & $\begin{array}{l}\text { F: ATTGGAGACCACTCTACCCTTTA } \\
\text { R: TGGATTCCCACATAGTCTACCG }\end{array}$ & 60.4 & (ATTT)n & $456-461$ & (11) \\
\hline TB16 & $\begin{array}{l}\text { F: TCCTTAGTATGGACTTGTTTGC } \\
\text { R: AGGATCACAGGGCAGGGAGACT }\end{array}$ & 58 & $((\mathrm{~A} / \mathrm{G}) \mathrm{AAG}) \mathrm{n}$ & $212-228$ & (11) \\
\hline TB20 & $\begin{array}{l}\text { F: TGATCTCCAAAGGCTTCTCCAT } \\
\text { R: GAACCTTCCCGTATGGGTCAGT }\end{array}$ & 60 & $(\mathrm{AAAAC}) \mathrm{n}$ & $221-237$ & (11) \\
\hline $\mathrm{TBC} 1$ & $\begin{array}{l}\text { F: TGGCAATTGGGAGAATTAGG } \\
\text { R: GCTGCCTTCATTCACCTCTC }\end{array}$ & 48 & (TG)n & 177 & (12) \\
\hline TBC3 & $\begin{array}{l}\text { F: TGGCAGGATTTCCTTCATTC } \\
\text { R: TCATTGCACGAGAATTTCCA }\end{array}$ & 44 & (GT)nGC (GT)n & 160 & (12) \\
\hline TBC5 & $\begin{array}{l}\text { F: GCTGCCTTCATTCACCTCTC } \\
\text { R: TGGCAATTGGGAGAATTAGG }\end{array}$ & 48 & $(\mathrm{AC}) \mathrm{nGCAG}(\mathrm{AC}) \mathrm{n}$ & 173 & (12) \\
\hline TBC10 & $\begin{array}{l}\text { F: CCTTACTGACCAGTGCTGAGG } \\
\text { R: GCCCAGACACAGAGAGGTTC }\end{array}$ & 52 & $\begin{array}{l}\text { (TGG)nCTGTA }(\mathrm{G}) \mathrm{n} \\
\mathrm{A}(\mathrm{GCTGGG}) \mathrm{n}\end{array}$ & $113-182$ & (12) \\
\hline TBC11 & $\begin{array}{l}\text { F: GACCTGGTGGCATGAAAACT } \\
\text { R: TCGGGGAAATATGGAGAGAA }\end{array}$ & 51.5 & $(\mathrm{GT}) \mathrm{nGC}(\mathrm{CT}) \mathrm{n}$ & $157-167$ & (12) \\
\hline TG1 & $\begin{array}{l}\text { F: TTCCTGTTACTCTGTTTTTTTCAGG } \\
\text { R: ACATGGCTAACTGTGTGCTTTG }\end{array}$ & 52 & $(\mathrm{CA}) \mathrm{n}$ & $152-183$ & AY-064160 \\
\hline TG4 & $\begin{array}{l}\text { F: TGAAAACTGGCAATTCATATGC } \\
\text { R: CAATCCTTTTTCGTTAGTTTTGTG }\end{array}$ & 52 & $\begin{array}{l}(\mathrm{CA}) \mathrm{nTA}(\mathrm{CA}) \mathrm{n} \\
\mathrm{TA}(\mathrm{CA}) \mathrm{n}\end{array}$ & 152 & AY-064161 \\
\hline TG19 & $\begin{array}{l}\text { F: ACCCCTCCCTAAAGGAACT } \\
\text { R: CGCCCTATAGAAACCTCTCC }\end{array}$ & 55 & (CA)nTAAA(CA)n & 171 & AY-064163 \\
\hline
\end{tabular}

PCR, polymerase chain reaction; $F$, forward; $R$, reverse.

polymorphic microsatellite loci in Tupaia belangeri chinensis, Tupaiaglis and Tupaia minor (2,12-14).

\section{Discussion}

A high level of genetic diversity is essential for the long-term survival of populations, and the extent of variation determines their ability to adapt to changing environments. The provision of the primers for these microsatellite markers facilitates the studies of population structure, gene flow, and mapping of the tree shrew genome. In the present study, we analyzed
16 microsatellite loci in 76 animals of wild Tupaia belangeri yaoshanensis and showed that these Tupaia belangeri yaoshanensis had a considerably high heterozygosity, suggesting that the 16 markers may be useful for individual discrimination and parentage testing, as well as for the quantification of population heterogeneity.

We also compared our results with the same microsatellite markers reported in other subspecies including T. glias, T. minor and Tupaia belangeri chinensis, and found some genetic differences between Tupaia belangeri yaoshanensis and other subspecies (12,12-14). Since there are six subspecies 
Table II. Polymorphic microsatellite markers identified in Tupaia belangeri yaoshanensis in this study.

\begin{tabular}{|c|c|c|c|c|c|c|}
\hline Locus & $N_{\mathrm{A}}$ & $N_{\mathrm{E}}$ & $H_{\mathrm{O}}$ & $H_{\mathrm{E}}$ & $F$ is & PIC \\
\hline $188^{\mathrm{a}}$ & 9.000 & 3.6098 & 0.6892 & 0.7279 & 0.0467 & 0.68 \\
\hline $196^{\circ}$ & 4.000 & 1.4777 & 0.1714 & 0.3256 & 0.4697 & 0.3052 \\
\hline $\mathrm{B} 2^{\mathrm{a}}$ & 10.000 & 3.6554 & 0.7714 & 0.7317 & -0.0 & 0.6849 \\
\hline B3 & 2.000 & 1.1573 & 0.1200 & 0.1368 & 0.1 & 0.1266 \\
\hline 38 & 2.000 & 1.2227 & 0.1486 & 0.1834 & 0.1 & 0.1656 \\
\hline$\Gamma \mathrm{B} 10^{\mathrm{a}}$ & 6.000 & 2.3112 & 0.0870 & 0.5715 & 0.8467 & 0.4739 \\
\hline TB16 & 4.000 & 1.6284 & 0.3194 & 0.3886 & 0.1722 & 0.3500 \\
\hline TB20a & 5.000 & 2.1457 & 0.4583 & 0.5277 & 0.1416 & 0.4417 \\
\hline ТВC $10^{\mathrm{a}}$ & 6.000 & 1.2344 & 0.1781 & 0.1912 & 0.0623 & 0.1817 \\
\hline $\mathrm{CBC} 11^{\mathrm{a}}$ & 5.000 & 3.2996 & 0.5 & 0.7 & & 0.6468 \\
\hline $\mathrm{C}$ & 8.00 & 4.6301 & 0.8947 & 0.7892 & -0.1412 & 0.7505 \\
\hline Mean & 5.5455 & 2.3975 & 0.3968 & 0.4796 & 0.1893 & 0.4378 \\
\hline
\end{tabular}

$N_{\mathrm{A}}$, observed number of alleles; $N_{\mathrm{E}}$, effective number of alleles; $H_{\mathrm{O}}$, observed heterozygosity; $H_{\mathrm{E}}$, expected heterozygosity; $F$ is, fixation index; PIC, polymorphism information content. ${ }^{\text {aSignificant }}$ deviations from Hardy-Weinberg equilibrium.

in Chinese tree shrews, further study is necessary to determine the genetic diversity of other subspecies, as well as the genetic relationship between the subspecies.

Recent studies have shown that microsatellite markers are useful as a tool in the investigation of population genetics, ecology, and conservation of the Tupaia belangeri yaoshanensis. Our data reported here provide further scientific basis for the identification, breeding, and laboratory animalization of Tupaia belangeri yaoshanensis, and should pave the way for making use of the Tupaia belangeri yaoshanensis in Guangxi with both scientific and economic value.

\section{Acknowledgements}

We gratefully acknowledge the assistance from the Laboratory of Molecular Medicine Teaching (Guangxi Medical University), and thank Ms. Y.-F.G. (Guangxi University) for helping with the data analysis. This study was supported by grants from the Department of Science and Technology of Guangxi (nos. GKG1347003-6 and 14123006-1) and the Key Laboratory for Complementary and Alternative Medicine Experimental Animal Models of Guangxi, the Department of Education of Guangxi.

\section{References}

1. Malvolti ME, Olimpieri I, Pollegioni P, Cseke K, Keserú Z and Rédei K: Black locust (Robinia pseudoacacia L.) root cuttings: diversity and identity revealed by SSR genotyping: A case study. South-east Eur Forestry 6: 201-217, 2017.

2. Srikwan S, Hufford K, Eggert L and Woodruff D: Variable microsatellite markers for genotyping tree shrews, Tupaia, and their potential use in genetic studies of fragmented populations. Sci Asia 28: 93-97, 2002.

3. Fuchs E and Corbach-Söhle S: Tree Shrews. In: The UFAW Handbook on the Care and Management of Laboratory and Other Research Animals. Hubrecht R and Kirkwood J (eds). 8th edition. Wiley-Blackwell, Oxford, pp262-275, 2010.

4. Sargis E: New views on tree shrews: The role of tupaiids in primate supraordinal relationships. Evol Anthropol 13: 56-66, 2004.

5. Müller S, Stanyon R, O'Brien PCM, Ferguson-Smith MA, Plesker R and Wienberg J: Defining the ancestral karyotype of all primates by multidirectional chromosome painting between tree shrews, lemurs and humans. Chromosoma 108: 393-400, 1999.

6. Emmons L: Tupai: A Field Study of Bornean Treeshrews. University of California Press, Berkeley, 2000.

7. Xu L, Chen SY, Nie WH, Jiang XL and Yao YG: Evaluating the phylogenetic position of Chinese tree shrew (Tupaia belangeri chinensis) based on complete mitochondrial genome: Implication for using tree shrew as an alternative experimental animal to primates in biomedical research. J Genet Genomics 39: 131-137, 2012.

8. O'Brien SJ, Menotti-Raymond M, Murphy WJ, Nash WG, Wienberg J, Stanyon R, Copeland NG, Jenkins NA, Womack JE and Marshall Graves JA: The promise of comparative genomics in mammals. Science 286: 458-462, 479-481, 1999.

9. Schmitz J, Ohme M and Zischler H: The complete mitochondrial genome of Tupaia belangeri and the phylogenetic affiliation of scandentia to other eutherian orders. Mol Biol Evol 17: 1334-1343, 2000

10. Bai CC, Liu SF, Zhuang ZM, Lin L, Wang H and Chang YQ: Isolation and characterization of microsatellite markers for the Korean rockfish, Sebastes schlegeli. Genet Mol Res 10: 2065-2068, 2011

11. Lin L, Zhu L, Liu SF, Tang QS, Su YQ and Zhuang ZM: Polymorphic microsatellite loci for Japanese Spanish mackerel (Scomberomorus niphonius). Genet Mol Res 11: 1205-1208, 2012.

12. Liu XH and Yao YG: Characterization of 12 polymorphic microsatellite markers in the Chinese tree shrew (Tupaia belangeri chinensis). Dongwuxue Yanjiu 34: E62-E68, 2013.

13. Li JX, Wang XX, Wang WG, Sun XM and Dai JJ: Isolation of microsatellite markers in tree shrews (Tupaia belangeri chinensis). Acta Laboratorium Animalis Sci Sin 19: 312-315, 2011.

14. Munshi SJ and Wilkinson GS: Isolation and characterization of polymorphic microsatellite loci in Bornean tree shrews (Tupaia spp.). Mol Ecol Notes 6: 698-699, 2006.

15. Yeh FC, Yang R, Boyle TJ and Ye Z: Popgene version 1.32 Microsoft Windows-based software for population genetic analysis: A quick user's guide. University of Alberta, Center for International Forestry Research, Alberta, 1999.

16. Botstein D, White RL, Skolnick M and Davis RW: Construction of a genetic linkage map in man using restriction fragment length polymorphisms. Am J Hum Genet 32: 314-331, 1980. 